\title{
Barium Titanium Oxynitride from Ammonia-Free Nitridation of Reduced $\mathrm{BaTiO}_{3}$
}

\author{
Hua Guo ${ }^{1} \oplus$, Aleksander Jaworski ${ }^{1}$, Zheng $\mathrm{Chen}^{2}$, Can $\mathrm{Lu}^{2}$, Adam Slabon ${ }^{1}$ and Ulrich Häussermann ${ }^{1, *}$ \\ 1 Department of Materials and Environmental Chemistry, Stockholm University, SE-10691 Stockholm, Sweden; \\ hua.guo@mmk.su.se (H.G.); aleksander.jaworski@mmk.su.se (A.J.); adam.slabon@mmk.su.se (A.S.) \\ 2 Institute of Inorganic Chemistry, RWTH Aachen University, Landoltweg 1, DE-52074 Aachen, Germany; \\ zheng.chen@ac.rwth-aachen.de (Z.C.); can.lu@ac.rwth-aachen.de (C.L.) \\ * Correspondence: ulrich.haussermann@mmk.su.se; Tel.: +46-08-162390
}

Citation: Guo, H.; Jaworski, A.;

Chen, Z.; Lu, C.; Slabon, A.;

Häussermann, U. Barium Titanium Oxynitride from Ammonia-Free Nitridation of Reduced $\mathrm{BaTiO}_{3}$. Inorganics 2021, 9, 62. https:// doi.org/10.3390/inorganics9080062

Academic Editor: Hiroshi Kageyama

Received: 28 June 2021

Accepted: 31 July 2021

Published: 5 August 2021

Publisher's Note: MDPI stays neutral with regard to jurisdictional claims in published maps and institutional affiliations.

Copyright: (c) 2021 by the authors. Licensee MDPI, Basel, Switzerland. This article is an open access article distributed under the terms and conditions of the Creative Commons Attribution (CC BY) license (https:// creativecommons.org/licenses/by/ $4.0 /)$.

\begin{abstract}
We investigated the nitridation of reduced $\mathrm{BaTiO}_{3}, \mathrm{BaTiO}_{2.60} \mathrm{H}_{0.08}$, corresponding to an oxyhydride with a large concentration of $\mathrm{O}$ defects $(>10 \%)$. The material is readily nitrided under flowing $\mathrm{N}_{2}$ gas at temperatures between 400 and $450{ }^{\circ} \mathrm{C}$ to yield oxynitrides $\mathrm{BaTiO}_{2.6} \mathrm{~N}_{x}(x=0.2-0.22)$ with a slightly tetragonally distorted perovskite structure, $a \approx 4.01$ and $c \approx 4.02 \AA$, and Ti partially remaining in the oxidation state III. The tetragonal structure was confirmed from Raman spectroscopy. ${ }^{14} \mathrm{~N}$ MAS NMR spectroscopy shows a single resonance at $270 \mathrm{ppm}$, which is typical for perovskite transition metal oxynitrides. However, largely different signal intensity for materials with very similar $\mathrm{N}$ content suggests $\mathrm{N} / \mathrm{O} /$ vacancy ordering when prolonging nitridation times to hours. Diffuse reflectance UV-VIS spectroscopy shows a reduction of the intrinsic band gap to $2.4-2.45 \mathrm{eV}$ compared to $\mathrm{BaTiO}_{3}(\sim 3.2 \mathrm{eV})$. Mott-Schottky measurements confirm n-type conductivity and reveal a slight negative shift of the conduction band edge from $-0.59 \mathrm{~V}\left(\mathrm{BaTiO}_{3}\right)$ to $\sim-0.65 \mathrm{eV}$.
\end{abstract}

Keywords: solid-state chemistry; mixed-anion compounds; barium titanate; oxyhydride; oxynitride; solid-state NMR; optical bandgap

\section{Introduction}

In $2012 \mathrm{Kobayashi}$ et al. reported that the simple perovskite $\mathrm{BaTiO}_{3}$ can be converted to $\mathrm{BaTiO}_{3-x} \mathrm{H}_{x}$ (with $\mathrm{H}$-contents up to $x \approx 0.6$ ) at comparatively mild temperatures, around $600{ }^{\circ} \mathrm{C}$, by hydride reduction [1]. The paramagnetic oxyhydride $\mathrm{BaTiO}_{3-x} \mathrm{H}_{x}$ attains a cubic structure in which $\mathrm{O}^{2-}$ and $\mathrm{H}^{-}$ions commonly-and as in a solid-solution-form the octahedral environment around Ti that is now in a mixed IV/III oxidation state. Shortly after, it was shown that due to the labile nature of the hydride species $\mathrm{BaTiO}_{3-x} \mathrm{H}_{x}$ represents a versatile precursor toward new mixed-anion compounds [2]. This includes low temperature conversion to heavily nitridized $\mathrm{BaTiO}_{3}$ by either ammonolysis (nitridation under a stream of $\mathrm{NH}_{3}$ ) but, remarkably, also nitridation with inert elemental $\mathrm{N}_{2}$ [2,3]. Because of the ease of activation of $\mathrm{N}_{2}, \mathrm{BaTiO}_{3-x} \mathrm{H}_{x}$ has been investigated as a potential catalyst for ammonia synthesis [4].

Nitridized $\mathrm{BaTiO}_{3}$ has been previously obtained from the ammonolysis of mixtures of $\mathrm{BaO}\left(\mathrm{BaCO}_{3}\right)$ and $\mathrm{TiO}_{2}$ at $950{ }^{\circ} \mathrm{C}$, which produced $\mathrm{BaTiO}_{2.85} \mathrm{~N}_{0.1}(0.57 \mathrm{wt} \% \mathrm{~N})$ [5]. By applying an excess of $\mathrm{BaO}$ nitrogen contents may be increased to $0.8 \mathrm{wt} \%$ [6]. The low-temperature conversion from reduced $\mathrm{BaTiO}_{3}$ precursors will give even higher $\mathrm{N}$ contents (up to $2.3 \mathrm{wt} \%$ as in $\mathrm{BaTiO}_{2.4} \mathrm{~N}_{0.4}$ [3]) and provide at the same time a broader range of compositions because of their variable $\mathrm{O}$ content, which can be-at least partiallycontrolled through the reaction conditions in the hydride reduction. Yet there have been only few investigations into the nitridation of reduced $\mathrm{BaTiO}_{3}$ and, in particular, little is known with respect to the properties of nitridized $\mathrm{BaTiO}_{3}$. According to Yajima et al. [3] and Masuda et al. [2] barium titanium oxynitride materials attain, depending on the $\mathrm{N}$ content, a cubic or a slightly distorted tetragonal simple perovskite structure. The tetragonal 
phases are non-centrosymmetric and ferroelectric. Temperature induced tetragonal-tocubic transition occurs at around $120^{\circ} \mathrm{C}$, which is close to that of $\mathrm{BaTiO}_{3}$.

Here we re-examine the nitridation of reduced $\mathrm{BaTiO}_{3}$ with $\mathrm{N}_{2}$. We point out that reduced $\mathrm{BaTiO}_{3}$ range from oxyhydrides where $\mathrm{O}^{2-}$ in the anion substructure is stoichiometrically replaced by $\mathrm{H}^{-}$(as in refs [1-3]) to materials with rather low contents of $\mathrm{H}$ and simultaneously large concentrations of $\mathrm{O}$ vacancies, $\mathrm{BaTiO}_{3-x} \mathrm{H}_{y} \square_{(x-y)}$. Hydride reduction of $\mathrm{BaTiO}_{3}$-involving the sintering of pelletized mixtures of $\mathrm{BaTiO}_{3}$ and metal hydride (e.g., $\mathrm{CaH}_{2}$ ) over prolonged periods of time-is not well understood, but it is most likely that $\mathrm{O}$-deficient forms $\mathrm{BaTiO}_{3-x}$ represent intermediates in the formation of oxyhydrides. Reactions conditions in hydride reductions can be varied by the choice and concentration/activity of metal hydride, reaction temperature, time and also the simultaneous presence of a (pressurized) $\mathrm{H}_{2}$ atmosphere [7-10]. Depending on conditions, highly O-deficient disordered cubic phases with $\mathrm{x}$ up to 0.6 and $\mathrm{y}$ in a range $0.04-0.25$ may be obtained $[10,11]$. We show that such O-deficient variants show equally high reactivity toward oxynitride formation as originally investigated $\mathrm{BaTiO}_{3-x} \mathrm{H}_{x}$. The sequence of materials conversions is sketched in Figure 1.
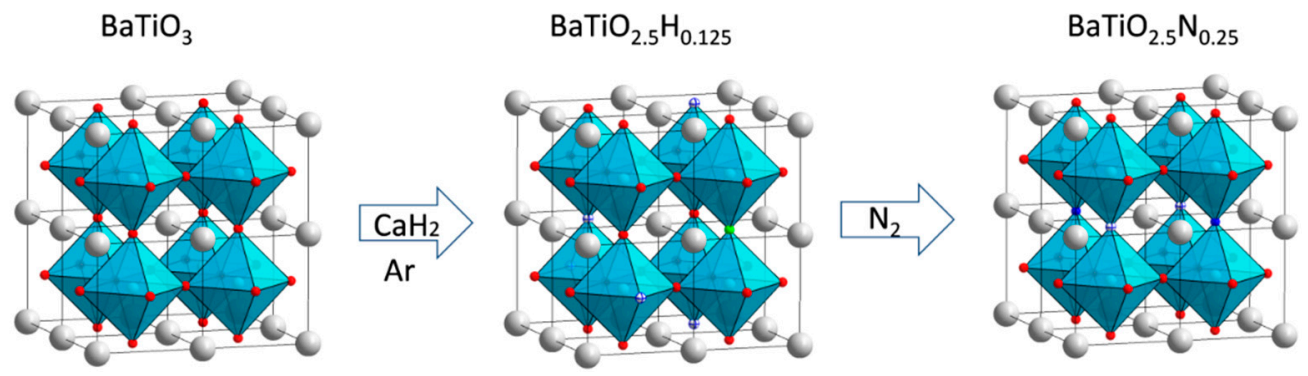

Figure 1. Sketch of material conversions: hydride reduction of $\mathrm{BaTiO}_{3}$ leading to an $\mathrm{O}$-deficient oxyhydride (exemplified as $\mathrm{H}$ /vacancy disordered $\mathrm{BaTiO}_{2.5} \mathrm{H}_{0.125}$ ) which then is nitridized with elemental nitrogen (exemplified as $\mathrm{BaTiO}_{2.5} \mathrm{~N}_{0.25}$ with an ordered (orthorhombic) N/vacancy arrangement). $\mathrm{Ba}, \mathrm{O}, \mathrm{H}, \mathrm{N}$ and vacancies are depicted as grey, red, green, blue, and white-blue circles, respectively.

\section{Results and Discussion}

\subsection{BTON Synthesis and Characterization}

The starting material for nitridation was obtained from reacting $\mathrm{BaTiO}_{3}$ with $\mathrm{CaH}_{2}$ at $550{ }^{\circ} \mathrm{C}$ for $48 \mathrm{~h}$ and corresponded to $\mathrm{BaTiO}_{2.60} \mathrm{H}_{0.08} \square_{0.32}$, in the following abbreviated as $\mathrm{BTOH}$. BTOH was characterized by powder X-ray diffraction (PXRD), thermogravimetric (TG) analysis, and ${ }^{1} \mathrm{H}$ Magic Angle Spinning (MAS) Nuclear Magnetic Resonance (NMR) spectroscopy. The TG curve is shown in Figure 2 whereas the PXRD and ${ }^{1} \mathrm{H}-\mathrm{MAS}$ NMR analyses are detailed as Supplementary Materials, Figures S1 and S2. The characterization results are summarized in Table 1 . BTOH has a cubic lattice parameter of $a=4.022 \AA$ resulting in a unit cell volume slightly higher than $\mathrm{BaTiO}_{3}$. From $\mathrm{TG}$ analysis the $\mathrm{H}$ content and/or $\mathrm{O}$ defect concentration of reduced $\mathrm{BaTiO}_{3}$ can be assessed [1,11,12]. An experiment under flowing air monitors the reactions $\mathrm{BaTiO}_{3-x} \mathrm{H}_{x}+0.75 x \mathrm{O}_{2} \rightarrow \mathrm{BaTiO}_{3}+0.5 x \mathrm{H}_{2} \mathrm{O}$ (1) and $\mathrm{BaTiO}_{3-x}+0.5 x \mathrm{O}_{2} \rightarrow \mathrm{BaTiO}_{3}$ (2). Typically there is a small initial weight loss (between 0.1 and $0.15 \%$ ) in the temperature range up to $300{ }^{\circ} \mathrm{C}$ which stems from the loss of surface hydroxyl and secondary water $[13,14]$. The onset of oxidation is seen at around $400{ }^{\circ} \mathrm{C}$. Oxidation appears to be completed above $650^{\circ} \mathrm{C}$ and leads to a weight increase of $2.79 \%$. The associated $x$ values according to Equations (1) and (2) are contained in Table 1. ${ }^{1} \mathrm{H}-\mathrm{MAS}-\mathrm{NMR}$ then revealed a rather small $\mathrm{H}$ content in $\mathrm{BTOH}, x \approx 0.08$, and accordingly $\mathrm{BTOH}$ possesses a high concentration of $\mathrm{O}$ defects. 


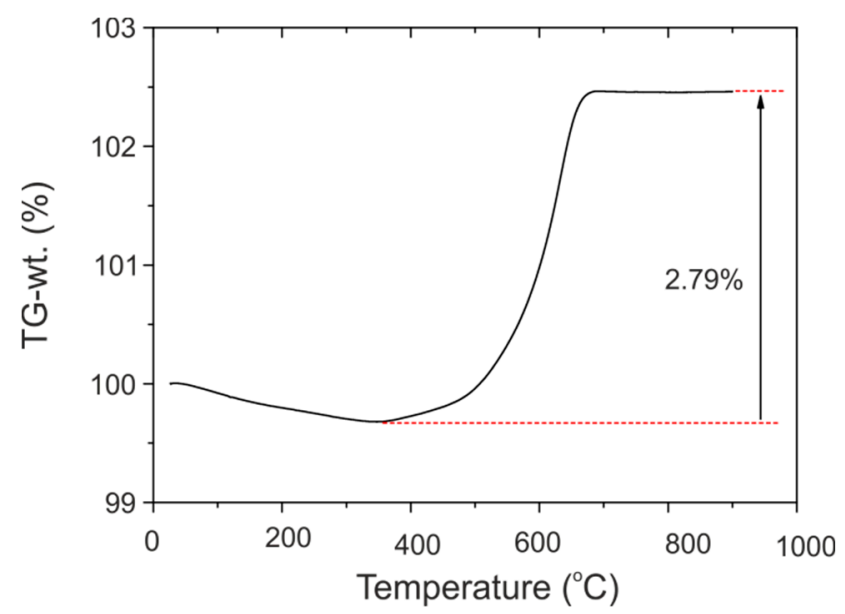

Figure 2. TG trace for BTOH upon heating under a dry air stream.

Table 1. Characterization summary for $\mathrm{BTOH}$.

\begin{tabular}{lccccccc}
\hline Sample & $\begin{array}{c}\text { Lattice } \\
\text { Parameters (̊) }\end{array}$ & $\begin{array}{c}\text { Volume } \\
\left(\AA^{3}\right)\end{array}$ & $\mathbf{X}_{\mathbf{T G}, \mathbf{H}} \mathbf{1}^{3}$ & $\mathbf{X}_{\mathbf{T G}, \square}{ }^{2}$ & $\mathbf{X}_{\mathrm{NMR}, \mathrm{H}}$ & $\mathbf{X}_{\square}$ & Formula \\
\hline $\mathrm{BaTiO}_{3}$ & $\begin{array}{c}a=3.9964(1) \\
c=4.0310(2)\end{array}$ & $64.379(2)$ & & & & & \\
\hline $\mathrm{BTOH}$ & $4.0220(2)$ & $65.062(1)$ & 0.422 & 0.396 & 0.08 & 0.32 & $\mathrm{BaTiO}_{2.60} \mathrm{H}_{0.08}$ \\
\hline
\end{tabular}

${ }^{1} \mathrm{X}_{\mathrm{TG}, \mathrm{H}}$ refers to the reaction $\mathrm{BaTiO}_{3-x} \mathrm{H}_{x}+0.75 x \mathrm{O}_{2} \rightarrow \mathrm{BaTiO}_{3}+0.5 x \mathrm{H}_{2} \mathrm{O} .{ }^{2} \mathrm{X}_{\mathrm{TG}, \square}$ refers to the reaction $\mathrm{BaTiO}_{3-x}$ $+0.5 x \mathrm{O}_{2} \rightarrow \mathrm{BaTiO}_{3}$.

Figure 3 shows combined TG and differential scanning calorimetry (DSC) traces of $\mathrm{BTOH}$ when heated in a stream of $\mathrm{N}_{2}$ to $500{ }^{\circ} \mathrm{C}$ (a) and $600{ }^{\circ} \mathrm{C}(\mathrm{b})$ at a rate of $10^{\circ} \mathrm{C} / \mathrm{min}$. The exothermic event at around $435^{\circ} \mathrm{C}$, concomitant with a weight increase of $0.99 \%$ and $1.38 \%$ respectively, is attributed to the formation of a nitridated phase, in the following abbreviated as BTON. The onset of nitridation occurs at a similar temperature as oxidation, perhaps relating to the activation of labile $\mathrm{H}^{-}$, but appears to be a sudden process compared to more gradual oxidation. Figure $3 \mathrm{c}$ compares TG traces of BTOH when heating for a prolonged period of time after reaching the target temperatures 500 and $600{ }^{\circ} \mathrm{C}$, respectively. There was no further weight increase with time in the $600{ }^{\circ} \mathrm{C}$ experiment, which implies that the nitridation reaction had already been completed when reaching this temperature. In the $500{ }^{\circ} \mathrm{C}$ experiment, continued weight increase was seen for about additionally $15 \mathrm{~min}$. At the same time the TG trace plateaued at a lower weight gain level, which suggests that the $600{ }^{\circ} \mathrm{C}$ experiment resulted in a product with a slightly higher $\mathrm{N}$ content (by $15 \%$ ). The $\mathrm{N}$ content corresponding to the TG weight increase is $x=0.19$ and 0.22 for the 500 and $600{ }^{\circ} \mathrm{C}$ experiment, respectively. The $\mathrm{N}$ content was also determined by chemical analysis for samples obtained at $600{ }^{\circ} \mathrm{C}$ without annealing (BTON-600C-0 h) and after $6 \mathrm{~h}$ prolonged nitridation (BTON-600C-6 h) and found to be in good agreement with the TG results. The characterization results for BTON samples are summarized in Table 2 and as Supplementary Materials. It is important to emphasize that nitridation experiments require strictly air-free conditions, otherwise (partial) oxidation will occur. In air BTON samples are stable up to about $400-500^{\circ} \mathrm{C}$. 

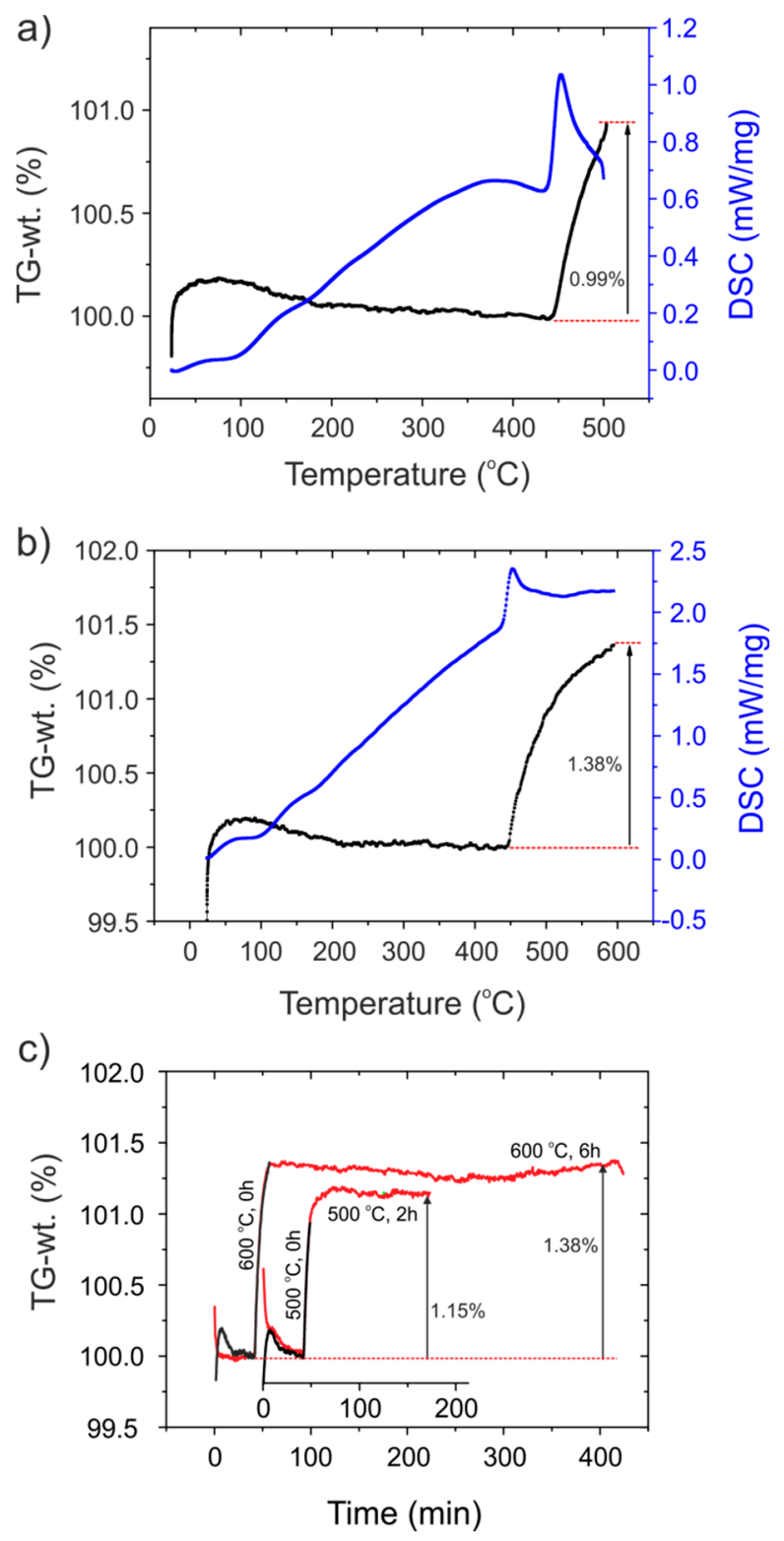

Figure 3. Simultaneously measured TG and DSC traces for BTOH upon heating under a dry $\mathrm{N}_{2}$ stream to $500{ }^{\circ} \mathrm{C}(\mathbf{a})$ and $600{ }^{\circ} \mathrm{C}(\mathbf{b})$. (c) TG traces upon prolonged nitridation at $500{ }^{\circ} \mathrm{C}(2 \mathrm{~h})$ and $600{ }^{\circ} \mathrm{C}(6 \mathrm{~h})$.

Table 2. Characterization summary for BTON. Samples are abbreviated as BTON-xxxC-yh where xxx indicates the nitridation temperature and $y$ the annealing time. Note that the tetragonal distortion has poor significance since the refinement of BTON PXRD patterns does not allow to discriminate between cubic and tetragonal phase when $c / a<1.003$.

\begin{tabular}{cccccc}
\hline Sample & Lattice Parameters $(\mathbf{A})$ & Volume $\left(\AA^{\mathbf{3}}\right)$ & $\mathbf{X}_{\text {TG, } \mathbf{N}}$ & $\mathbf{X}_{\text {chem.anal.,N }}$ & Formula \\
\hline BTON-600C-0 h & $\begin{array}{l}a=4.0086(3) \\
c=4.0180(5)\end{array}$ & $64.630(2)$ & 0.22 & 0.20 & $\mathrm{BaTiO}_{2.60} \mathrm{~N}_{0.20} \square_{0.20}$ \\
\hline BTON-600C-6 h & $\begin{array}{l}a=4.0085(3) \\
c=4.0184(2)\end{array}$ & $64.533(2)$ & 0.21 & 0.18 & $\mathrm{BaTiO}_{2.60} \mathrm{~N}_{0.18} \square_{0.22}$ \\
\hline
\end{tabular}

The composition of nitridized $\mathrm{BaTiO}_{3}$ can be expressed as $\mathrm{BaTiO}_{3-x} \mathrm{~N}_{2 x / 3}$. Accordingly, the inherent $\mathrm{O}$ defect concentration is $x / 3$ [3]. The upper limit for $x$ for reduced $\mathrm{BaTiO}_{3}$ appears to be $x \approx 0.6$ [1]. Thus the composition $\mathrm{BaTiO}_{2.4} \mathrm{~N}_{0.4}$, as reported by Yajima et al. [3], should represent the highest achievable $\mathrm{N}$ content for $\mathrm{Ba}$ oxynitrides. With our $\mathrm{BTOH}$ 
starting material, the composition after nitridation was expected to be $\mathrm{BaTiO}_{2.6} \mathrm{~N}_{0.267}$. This $\mathrm{N}$ content is clearly not achieved, which implies that Ti partially remains as $\mathrm{Ti}^{3+}$ (about $5 \%$ ). Thus, our BTON materials should be paramagnetic and possibly metallic. To accommodate for this situation, the formula for nitridized $\mathrm{BaTiO}_{3}$ is rewritten as $\mathrm{BaTiO}_{3-x} \mathrm{~N}_{(2 x / 3)-y} \square_{(x / 3)+y}$ where $y=0$ refers to the stoichiometric, diamagnetic case. The application of higher nitridation temperatures and/or changed heating rates did not result in fully nitridized BTON samples (cf. Supplementary Materials, Figure S3).

Figure 4 shows scanning electron microscopy (SEM) images of the materials constituting the sequence of conversions (cf. Figure 1). The average particle size of tetragonal $\mathrm{BaTiO}_{3}$ used for hydride reduction was specified by the manufacturer as 0.5 micron. This is confirmed in Figure 4a, although some particle size distribution is noticeable. The particle morphology of $\mathrm{BaTiO}_{3}$ is retained in $\mathrm{BTOH}$ (Figure 4b). However, upon nitridation the surface topography of particles becomes noticeable changed (Figure 4c,d). The step-like features suggest recrystallization, involving ion transport during the solid-gas reaction. Thus the nitridation process of reduced $\mathrm{BaTiO}_{3}$ may not be truly topochemical.
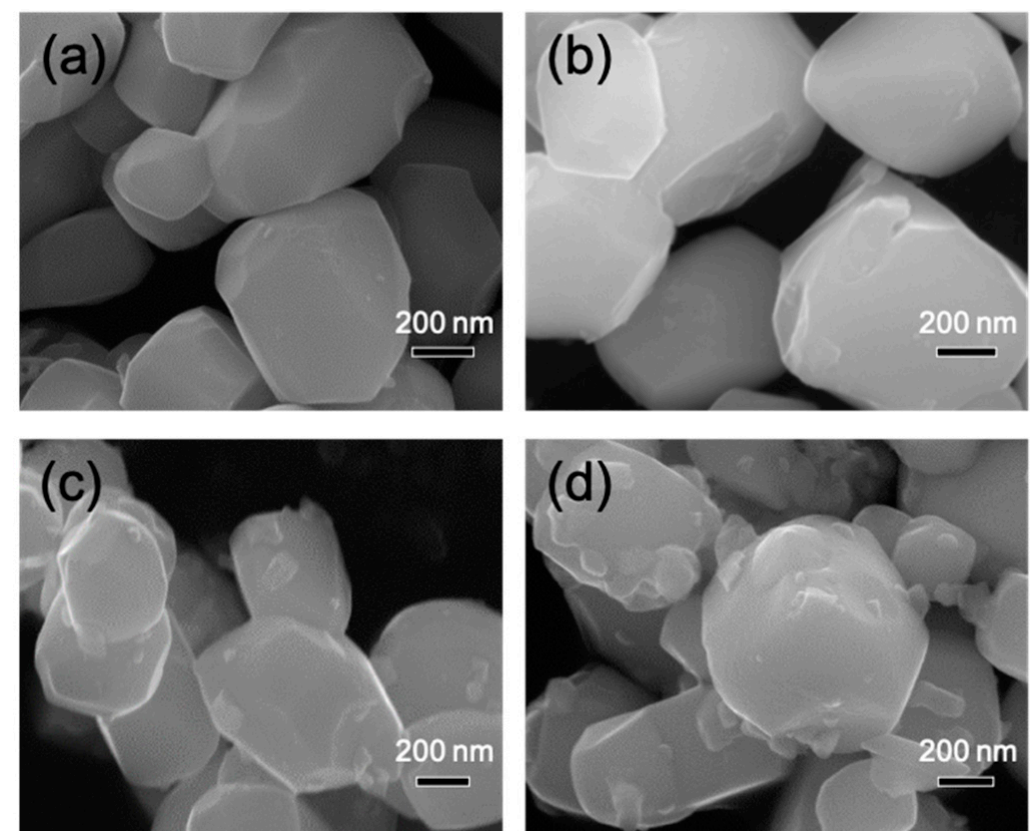

Figure 4. SEM images of $\mathrm{BaTiO}_{3}$ employed for hydride reduction (a), of BTOH (b), of BTON-600C-0 h (c), and BTON-600C-6 h (d).

Figure 5a depicts the changes of PXRD patterns and sample colors when going from $\mathrm{BaTiO}_{3}$ to BTOH to BTON. Detailed results of Rietveld refinements are presented as Supplementary Materials (Figures S4-S13, Tables S1 and S2). The tetragonal structure of $\mathrm{BaTiO}_{3}$ is clearly noticeable in the laboratory PXRD pattern, $a=3.996, c=4.031 \AA$ $(c / a=1.009)$, whereas the patterns for BTOH and BTON appear cubic, with the unit cell volume of BTON slightly smaller. Compared to BTOH one could infer a slight broadening of the reflections (200), (201), (211) (in the $2 \theta$ range $20-40^{\circ}$ ), which most clearly would show the tetragonal split. However, the refinement of laboratory data does not allow for discrimination between cubic and tetragonal phase $(c / a<1.003)$, Figure $5 b$. The tetragonal structure of BTON is then clearly revealed from Raman spectroscopy, as shown in Figure 6. Thus, we chose to present the result of the tetragonal refinement $(c / a \approx 1.002(2))$ in Table 2 , whereas the result of the cubic refinements is given in Table S2. 
a)

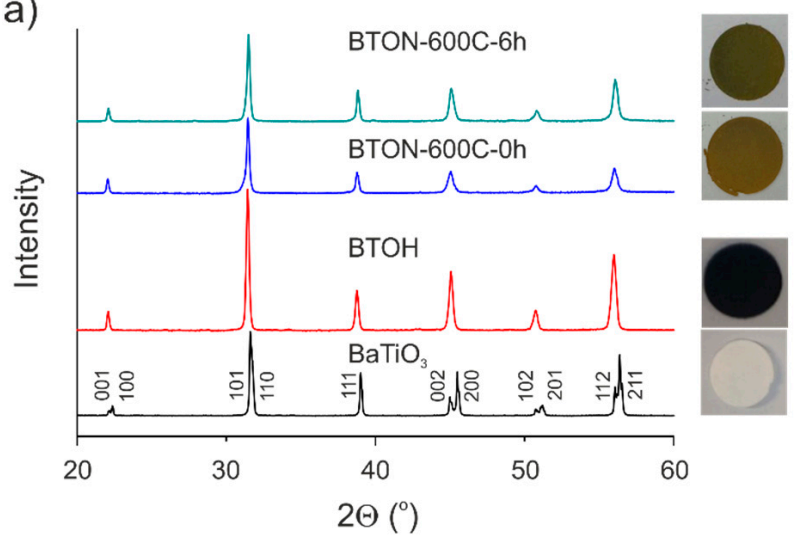

b)

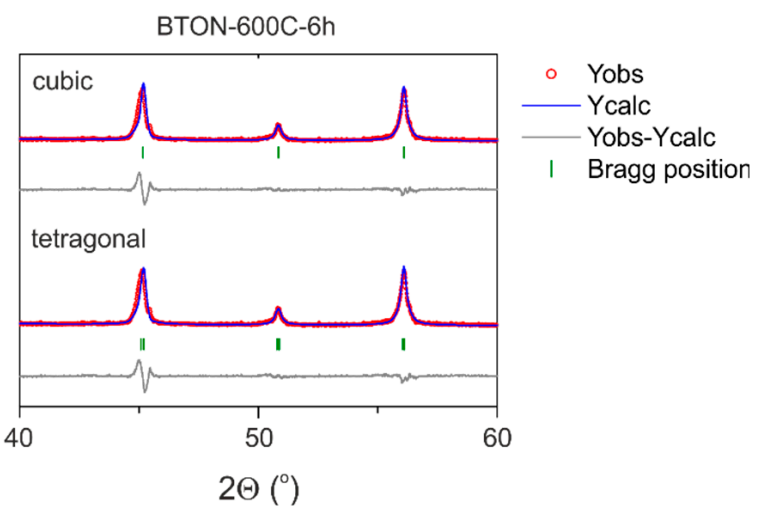

Figure 5. (a) PXRD patterns of $\mathrm{BaTiO}_{3}$ employed for hydride reduction, $\mathrm{BTOH}, \mathrm{BTON}-600 \mathrm{C}-0 \mathrm{~h}$, and $\mathrm{BTON}-600 \mathrm{C}-6 \mathrm{~h}$, with pictures on the right illustrating the sample colors. (b) Section of Rietveld plots for the PXRD pattern of BTON-600C-6 $\mathrm{h}$ when fitting a cubic structure $\left(a=4.0111(2), \chi^{2}=4.90, \mathrm{R}_{\mathrm{Bragg}}=4.71, \mathrm{R}_{\mathrm{F}}=3.25\right)$ and tetragonal structure $(a=4.0085(3)$, $\left.c=4.0184(2), \chi^{2}=4.25, \mathrm{R}_{\text {Bragg }}=5.45, \mathrm{R}_{\mathrm{F}}=3.66\right)$.

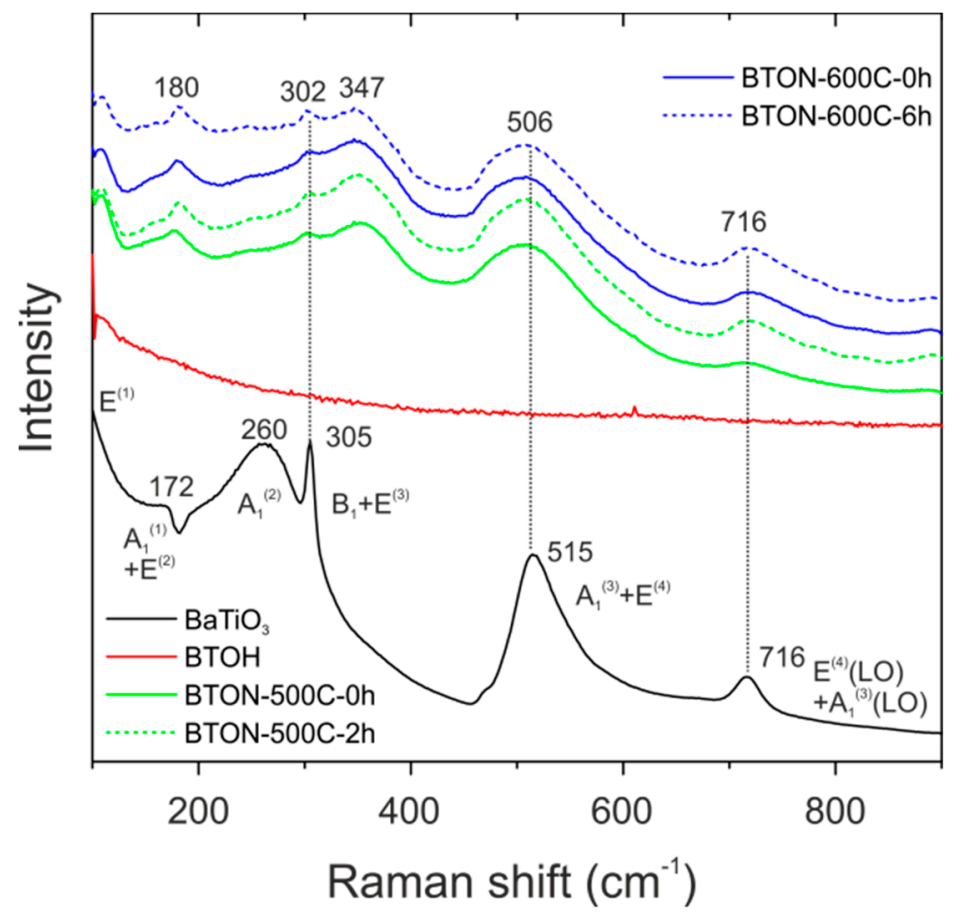

Figure 6. Compilation of Raman spectra for $\mathrm{BaTiO}_{3}, \mathrm{BTOH}, \mathrm{BTON}-500 \mathrm{C}-0 \mathrm{~h}, \mathrm{BTON}-500 \mathrm{C}-2 \mathrm{~h}$, BTON-600C-0 h, and BTON-600C-6 h.

The Raman spectrum of tetragonal $\mathrm{BaTiO}_{3}$ is well understood [15-17]. All twelve optical modes $3 \times \mathrm{A}_{1}+\mathrm{B}_{1}+4 \times \mathrm{E}$ are Raman active. Poly/nanocrystalline samples are characterized by sharp bands at about 170 and $305 \mathrm{~cm}^{-1}$ and asymmetric broader bands at about 260,515 , and $720 \mathrm{~cm}^{-1}[18,19]$. Furthermore, a pronounced dip at around $180 \mathrm{~cm}^{-1}$ is also characteristic, which has been attributed to interference from anharmonic coupling between three $A_{1}$ modes [15]. Lastly, the $E_{1}$ softmode ( $x, y$ displacement of Ti) expresses itself with a sharp rise of Raman scattering intensity at lowest wavenumbers [19]. The $\mathrm{BTOH}$ spectrum is featureless, in agreement with a cubic perovskite structure where all modes are Raman inactive. The Raman spectra of the BTON samples show broad bands at 347,506 and $716 \mathrm{~cm}^{-1}$ and sharp bands at 100, 180 and $302 \mathrm{~cm}^{-1}$. The latter (assigned to the non-polar $B_{1}$ mode) is characteristic for a tetragonal phase [20,21]. The same holds true for the band at $720 \mathrm{~cm}^{-1}$ which would be extremely broad and week in the cubic para-electric 
phase [20]. Because of the considerably lower tetragonality of the BTON phases compared to $\mathrm{BaTiO}_{3}$, bands are generally broader and weaker. However, there are two clear major differences. The softmode in $\mathrm{BaTiO}_{3}$ appears stiffened and the corresponding band is at around $100 \mathrm{~cm}^{-1}$ in the spectra of the BTON phases. Further, the band at around $260 \mathrm{~cm}^{-1}$ in $\mathrm{BaTiO}_{3}\left(\mathrm{~A}_{1}{ }^{(2)}\right)$ is not apparent in $\mathrm{BTON}$ and instead a band at $347 \mathrm{~cm}^{-1}$ is visible. The $\mathrm{A}_{1}{ }^{(2)}$ mode is the mutual displacement of $\mathrm{Ba}$ atoms and the $\mathrm{TiO}_{6 / 2}$ octahedron framework in the $\mathrm{z}$ direction [19]. It is not clear why this mode has either a very low intensity for BTON or is possibly blue-shifted by almost $90 \mathrm{~cm}^{-1}$.

The Raman spectra of the four different BTON samples are very much alike (possibly that the $B_{1}$ peak at $\sim 302 \mathrm{~cm}^{-1}$ is somewhat sharper for the annealed samples, especially for BTON-600C-6 h). This is in contrast with ${ }^{14} \mathrm{~N}-\mathrm{MAS}-\mathrm{NMR}$ spectra, shown in Figure 7 . The nuclear quadrupole moment of the ${ }^{14} \mathrm{~N}$ isotope implies drastic broadening of the resonance lines unless $\mathrm{N}$ is in a highly symmetric environment for which the quadrupolar coupling constant is relatively small. This is the case for perovskite oxynitrides and ${ }^{14} \mathrm{~N}-\mathrm{MAS}$ NMR has been used previously to probe N [5,22-24]. Somewhat surprising and still not explained, ${ }^{14} \mathrm{~N}$ expresses as a single resonance at $270 \mathrm{ppm}$, regardless the kind of transition metal ( $\mathrm{Ti}, \mathrm{Nb}, \mathrm{Ta}$ ) or $A$ component ( $\mathrm{Ca}, \mathrm{Sr}, \mathrm{Ba}, \mathrm{La}, \mathrm{Ce}$ ) in the perovskite oxynitride [25]. In our spectra the 270 ppm resonance is clearly there, but the signal intensity is considerably less for BTON-600-0 h compared to BTON-600C-6 h although the two materials possess virtually the same $\mathrm{N}$ content. We speculate that quadrupolar coupling is rather large for BTON-600C-0 $\mathrm{h}$ and that prolonged nitridation at $600{ }^{\circ} \mathrm{C}$ resulted in a more ordered $\mathrm{N} / \mathrm{O} /$ vacancy structure for BTON-600C-6 h (cf. Figure 1c). ${ }^{1} \mathrm{H}-\mathrm{MAS}-\mathrm{NMR}$ spectra show clearly the absence of hydridic H in BTON-600-0h and BTON-600-6h. As earlier shown, hydridic $\mathrm{H}$ as part of the bulk structure can be discriminated from protic $\mathrm{H}$ (from (surface) hydroxyl and secondary water) as negative and positive chemical shift contributions, respectively [11,12]. Hydric $H$ expresses itself as a single broad resonance peak at negative chemical shift whereas protic resonances appear at $\sim 1 \mathrm{ppm}$ (surface $\mathrm{OH}$ species) and in the region 6-7 ppm (secondary water). Interestingly one can recognize two $\mathrm{H}^{-}$environments for $\mathrm{BTOH}$, one centered at $-4 \mathrm{ppm}$ and one at $-55 \mathrm{pm}$. The occurrence of two hydridic environments in reduced $\mathrm{BaTiO}_{3}$ is highly unusual and perhaps relates to the large $\mathrm{O}$ defect concentration of BTOH (see Supplementary Materials for more details). Although the phenomenon is interesting and deserves more detailed investigations, it is not considered important for the outcome of the nitridation reactions.

\subsection{Spectroscopic and Mott-Schottky Analysis}

It is well known that $\mathrm{BaTiO}_{3}$ is a wide gap semiconductor with a band gap energy of 3.2-3.4 eV [26,27]. According to first principles calculations, the band gap is indirect for the tetragonal form and direct for the cubic (high temperature) polymorph [28]. However, experimentally it appears to be difficult to assign the nature of the band gap and frequently a direct band gap is also assumed for the tetragonal form. Mixed anion oxynitrides show reduced band gaps, by ca $1 \mathrm{eV}$, since the top of the valence band constitutes $\mathrm{N}-2 \mathrm{p}$ based states, which are at higher energy than O-2p [29]. Perovskite oxynitrides involving Ti are typically based on lanthanoid metals as the perovskite $A$ component and $A \mathrm{TiO}_{2} \mathrm{~N}$ ( $A=\mathrm{La}, \mathrm{Nd}, \mathrm{Ce}, \mathrm{Pr}, \mathrm{Eu}$ ) have been extensively investigated because of their photocatalytic activity and dielectric properties [30-32]. As outlined above, when $A$ corresponds to an alkaline earth metal, the reduced valence has to be compensated with defects in the anion substructure, i.e., $\mathrm{BaTiO}_{3-x} \mathrm{~N}_{(2 x / 3)-y} \square_{(x / 3)+y}$ where $y=0$ refers to the fully nitridized, diamagnetic case. For these materials properties are not well investigated. 


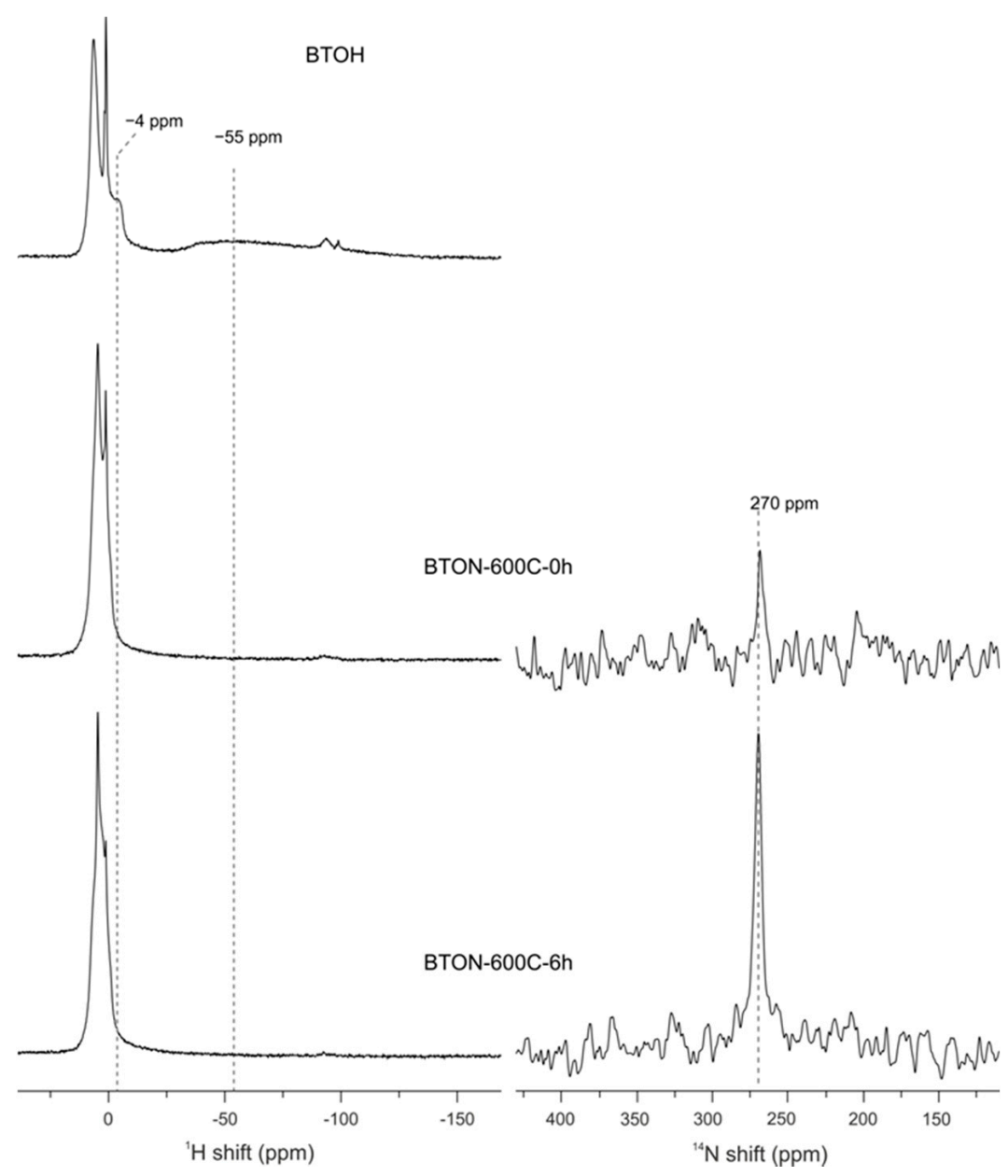

Figure 7. Compilation of MAS-NMR spectra for BTON and BTON-600C-0 h, and BTON-600C-6 h. Left panel: ${ }^{1} \mathrm{H}$ spectra. Right panel: ${ }^{14} \mathrm{~N}$ spectra. The broken vertical lines indicate the position of resonances of hydridic $\mathrm{H}$ (left) and $\mathrm{N}$ (right).

Figure 8 compares the UV-VIS diffuse reflectance spectra of the BTON-500C and BTON-600C samples with $\mathrm{BTOH}$ and pristine $\mathrm{BaTiO}_{3}$. As earlier reported, reduced $\mathrm{BaTiO}_{3}$ materials exhibit a broad absorption in the visible and near-IR region (Figure 8a) [12]. The actual absorption edge, corresponding to interband transitions, is around $400 \mathrm{~nm}$, which corresponds well to the band gap energy of $\mathrm{BaTiO}_{3}$. The near IR-VIS absorption enters a minimum upon approaching the upturn of the absorption edge, which is typical of (intraband) free carrier absorption in heavily doped semiconductors [33]. In metallic BTOH states at the bottom of the conduction band are occupied. The absorption edge of BTON is significantly red-shifted. In addition, the exponential onset of absorption indicates that charge carriers are localized in traps below the conduction band [34]. So in contrast with reduced $\mathrm{BaTiO}_{3}$ where electrons form delocalized band states [35], they appear localized in polarons in not fully nitridized BTON. 
a)

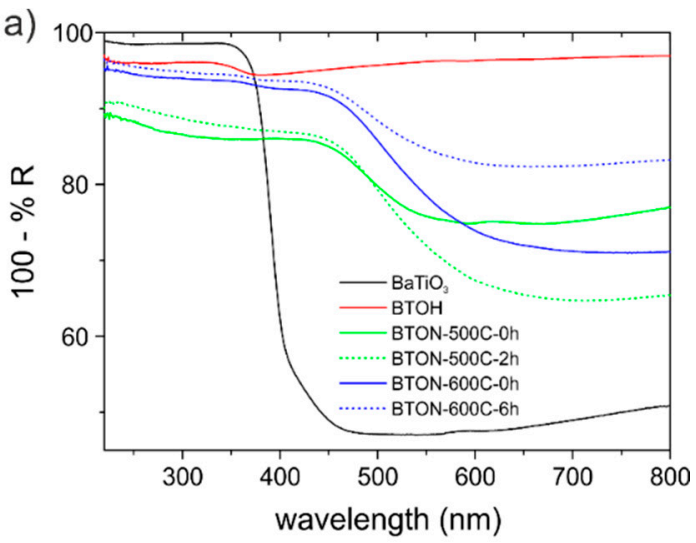

b)

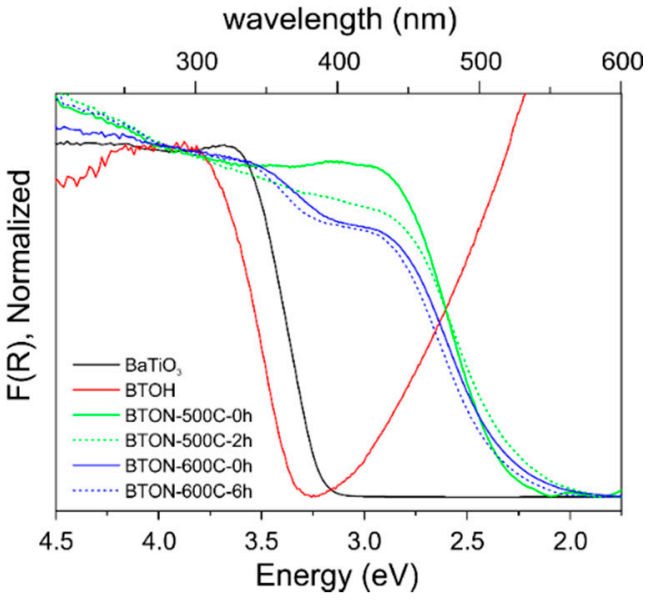

Figure 8. (a) Diffuse reflectance UV-VIS spectra of $\mathrm{BaTiO}_{3}, \mathrm{BTOH}, \mathrm{BTON}-500 \mathrm{C}-0 \mathrm{~h}, \mathrm{BTON}-500 \mathrm{C}-2 \mathrm{~h}$, BTON-600C-0 h, and BTON-600C-6 h. (b) Normalized Kubelka-Munk function of the spectra.

Figure 8b shows the Kubelka-Munk (K-M) transformed spectra, which-for comparability across the samples-was normalized. The $\mathrm{K}-\mathrm{M}$ transformed spectrum of metallic $\mathrm{BTOH}$ is different from the BTON materials because of the free carrier absorption. Its absorption edge is slightly (by $0.1 \mathrm{eV}$ ) shifted upwards compared to $\mathrm{BaTiO}_{3}$, which is in line with earlier observations [12]. The absorption edge of BTON is in a range $500-550 \mathrm{~nm}$. Tauc plots (presented as Supplementary Materials, Figure S14) suggest band gaps in a range $2.4-2.5 \mathrm{eV}$ as summarized in Table 3, which agrees with the green-yellow color of the material.

Mott-Schottky measurements were carried out for BTON-600-0 $\mathrm{h}$ and BTON-600-6 h as well as the $\mathrm{BTOH}$ precursor and the results compared with pristine $\mathrm{BaTiO}_{3}$ (Figure 9). All materials show a positive slope, confirming the semiconducting n-type behavior. The flat band potential of $\mathrm{BaTiO}_{3}$ is $-0.59 \mathrm{~V}$ vs. Reversible Hydrogen Electrode (RHE). In case of a n-type semiconductor, the flat band potential is close to the bottom of the conduction band [36]. BTOH exhibits a flat band potential at $-0.54 \mathrm{~V}$ vs. RHE. A slight positive shift of the flat potential, which may reach up to $-0.36 \mathrm{~V}$ compared to the pristine $\mathrm{BaTiO}_{3}$, has also been observed for other reduced materials $\mathrm{BaTiO}_{3-x} \mathrm{H}_{y} \square_{(x-y)}$ with different $x, y$ [12]. In contrast, BTON displays a negative shift $-0.65 \mathrm{~V}$, without any significant difference between the differently annealed samples (cf. Table 3). The slopes of $\mathrm{BaTiO}_{3}$ and $\mathrm{BTOH}$ are very similar, although the charge carrier density of the latter is considerably higher. Since the slope is also depending on the dielectric constant, this was explained with a much smaller dielectric constant of cubic BTOH [12]. The dielectric constant of tetragonal BTON will relate more to that of tetragonal $\mathrm{BaTiO}_{3}$ and, thus, the smaller slope compared to $\mathrm{BaTiO}_{3}$ reflects its higher charge carrier density. 


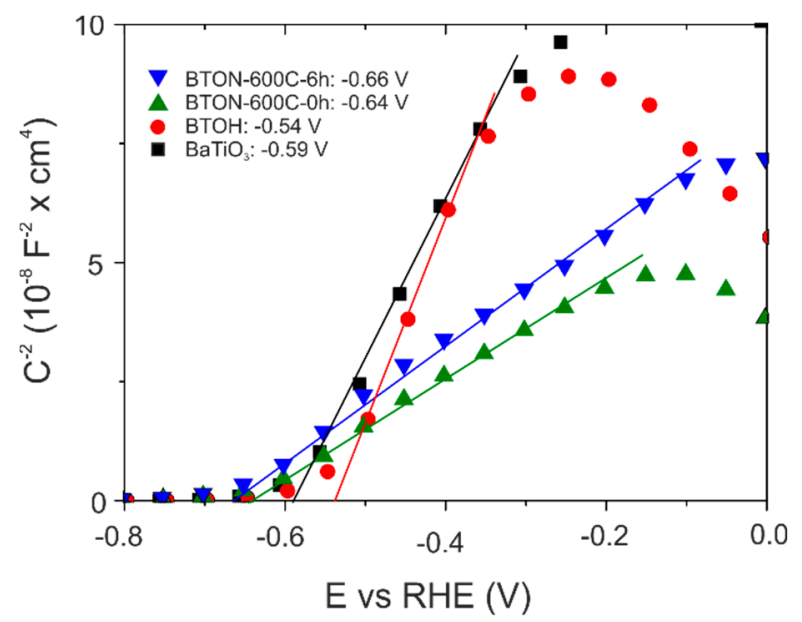

Figure 9. Mott-Schottky plots of $\mathrm{BaTiO}_{3}, \mathrm{BTOH}, \mathrm{BTON}-600 \mathrm{C}-0 \mathrm{~h}$, and BTON-600C-6 h.

Table 3. Compilation of bandgaps and flat band potentials.

\begin{tabular}{ccc}
\hline Sample & $\begin{array}{c}\text { Bandgap (eV) } \\
\text { (Direct) }\end{array}$ & Flat Band Potential (vs. RHE, V) \\
\hline $\mathrm{BaTiO}_{3}$ & 3.18 & -0.59 \\
$\mathrm{BTOH}$ & 3.33 & -0.54 \\
BTON-600-0 h & 2.45 & -0.64 \\
BTON-600-6 h & 2.46 & -0.66 \\
\hline
\end{tabular}

\section{Materials and Methods}

\subsection{Synthesis of the Materials}

As starting materials we used $\mathrm{BaTiO}_{3}(500 \mathrm{~nm}$ particle size, $99.9 \%$ purity, $\mathrm{ABCR} \mathrm{GmbH}$, Karlsruhe, Germany) and $\mathrm{CaH}_{2}$ powder (95\%, Sigma Aldrich, Darmstadt, Germany). Prior to use, $\mathrm{BaTiO}_{3}$ was dried overnight in an oven at $200{ }^{\circ} \mathrm{C}$. All steps of sample preparation were performed in an Ar filled glove box. For a typical synthesis $\sim 0.25 \mathrm{~g}(1.05 \mathrm{mmol})$ of $\mathrm{BaTiO}_{3}$ was intimately mixed with $0.053 \mathrm{~g}(2.36 \mathrm{mmol}) \mathrm{CaH}_{2}$, i.e., the $\mathrm{BaTiO}_{3}: \mathrm{H}$ ratio was about 4.5. The $\mathrm{BaTiO}_{3} / \mathrm{CaH}_{2}$ mixture was subsequently pressed into a pellet with a diameter of $9 \mathrm{~mm}$. The pellet was then sealed inside a stainless steel ampule (with dimensions $10 \mathrm{~mm}$ ID and $50 \mathrm{~mm}$ length), which-after removal from the glove boxwas placed in a box furnace. A K-type thermocouple was inserted and located in close proximity to the metal ampule. Ampules were heated for $48 \mathrm{~h}$ at $550{ }^{\circ} \mathrm{C}$. After cooling to room temperature, ampules were opened and the products washed with $0.1 \mathrm{M}$ acetic acid (HAc) solution to remove excess $\mathrm{CaH}_{2}$ and metal oxide/hydroxide formed during hydride reduction. For washing, the pellets were crushed and sonicated with $50 \mathrm{~mL}$ HAc and then centrifuged. The procedure was repeated 3 times. As a last step, products were treated with $20 \mathrm{~mL} 95 \%$ ethanol and then dried at $120^{\circ} \mathrm{C}$ under dynamic vacuum $\left(<10^{-5} \mathrm{bar}\right)$. The dried product corresponded to dark blue powder. Portions of about $20 \mathrm{mg}$ of the so obtained oxyhydride material were then heated in a $100 \mathrm{~mL} / \mathrm{min}$ nitrogen stream $(99.9999 \%(6 \mathrm{~N})$ purity) at a rate of $10^{\circ} \mathrm{C} / \mathrm{min}$ to various temperatures using a Netzsch ${ }^{\circledR}$ STA 449 F1 Jupiter thermal analysis apparatus (Netzsch, Selb, Germany). The reactions were protected by an oxygen getter to avoid oxidation of oxyhydride materials. The color or the products after nitridation was changed to yellow-green (cf. Figure 5a).

\subsection{Powder X-ray Diffraction (PXRD) Analysis}

PXRD patterns were collected on a Panalytical X'Pert PRO diffractometer (Malvern Panalytical, Malvern, UK) operated with $\mathrm{Cu} \mathrm{K} \alpha$ radiation and in $\theta-2 \theta$ diffraction geometry. Powder samples were mounted on a Si wafer zero-background holder and diffraction patterns measured in a $2 \theta$ range of $20-120^{\circ}$ with $0.016^{\circ}$ step size. The contribution of $\mathrm{K} \alpha_{2}$ 
radiation to the PXRD patterns was removed using the Panalytical X'Pert HighScore Plus software (Malvern Panalytical, Malvern, UK). The Rietveld method as implemented in the FullProf program was used for structure and phase analysis [37]. A six-coefficient polynomial function was applied for the background. The peak shape was described by a Pseudo-Voigt function. Site occupancies for the $\mathrm{O}$ atoms could not be refined reliably and were constrained to 1 .

\subsection{Scanning Electron Microscopy (SEM) Investigations}

SEM investigations were carried out using a JEOL JSM-7000F microscope (Jeol, Tokyo, Japan) equipped with a Schottky-type field emission gun (Oxford Instruments, Oxfordshire, UK). Images were recorded in second-electron mode with an accelerating voltage of $15 \mathrm{kV}$. Samples were prepared by first producing a homogeneous suspension of particles in ethanol by sonication. Then droplets of the suspension were applied onto surface-polished Aluminum pin stubs and left to dry.

\subsection{Raman Spectroscopy}

Raman spectra were measured using a Labram HR 800 spectrometer (Horiba, Kyoto, Japan) equipped with an $800 \mathrm{~mm}$ focal length spectrograph and an air cooled, back thinned CCD detector. Powdered sample was placed on a glass slide and excited with a double frequency Nd:YAG laser $(532 \mathrm{~nm})$. To avoid decomposition/oxidation the lowest possible laser power (ND filter $1 \%$, corresponding to a power density of $5.5 \times 10^{-6} \mathrm{~mW} \cdot \mu \mathrm{m}^{-2}$ ) was applied for the oxyhydride and oxynitride samples. Spectra were collected at room temperature in a range $0-1800 \mathrm{~cm}^{-1}$ and using a grating of 600 lines $/ \mathrm{mm}$. For oxynitride samples large exposure times (of up to $25 \mathrm{~min}$ ) were employed.

\subsection{Thermogravimetric Analysis (TGA)}

TGA experiments were carried out using a TA instruments Discovery system (TA Instruments, New Castle, DE, USA). The samples ( $15 \mathrm{mg}$ powders) were heated in a platinum crucible from room temperature to $900{ }^{\circ} \mathrm{C}$ with a heating rate of $10{ }^{\circ} \mathrm{C} / \mathrm{min}$. A dry air gas flow of $20 \mathrm{~mL} / \mathrm{min}$ was applied.

\subsection{Chemical Analysis}

Elemental analysis of $\mathrm{N}$ was performed by Mikroanalytisches Labor Kolbe (www. mikro-lab.de, accessed on 12 April 2021) using a CHN-(combustion) analyzer from Elementar (model "vario MICRO cube", Elementar Analysensysteme GmbH, Langenselbold, Germany).

\subsection{UV-VIS Diffuse Reflectance Spectroscopy}

UV-VIS diffuse reflectance measurements were performed at room temperature on finely ground samples. Spectra were recorded in the range from 200 to $800 \mathrm{~nm}$ with an Agilent Cary 5000 UV-VIS-NIR spectrometer (Agilent, Santa Clara, CA, USA) equipped with a diffuse reflectance accessory from Harrick (Harrick Scientific Products Inc, New York, NY, USA). A polytetrafluoroethylene (PTFE) pellet (100\% reflectance) was used as the reference.

\subsection{Magic Angle Spinning (MAS) NMR Spectroscopy}

The ${ }^{1} \mathrm{H}$ and ${ }^{14} \mathrm{~N}$ MAS NMR experiments were performed at a magnetic field of $14.1 \mathrm{~T}$ (600.1 and 43.4 MHz Larmor frequencies for ${ }^{1} \mathrm{H}$ and ${ }^{14} \mathrm{~N}$, respectively) and MAS frequency of $60.00 \mathrm{kHz}$ on a Bruker Avance-III spectrometer (Bruker, Billerica, MA, USA) equipped with a $1.3 \mathrm{~mm}$ MAS HX probe. Proton spectra were acquired using a rotor-synchronized, double-adiabatic spin-echo sequence with a $90^{\circ}$ excitation pulse of $1.1 \mu \mathrm{s}$ followed by a pair of $50 \mu \mathrm{s} \tanh / \tan$ short high-power adiabatic pulses (SHAPs) with $5 \mathrm{MHz}$ frequency sweep [38,39]. All pulses were applied at a nutation frequency of $210 \mathrm{kHz}$. In total, 256 signal transients with a $5 \mathrm{~s}$ recycle delay were accumulated for each sample. The 


\begin{abstract}
${ }^{14} \mathrm{~N}$ MAS spectra were collected using a Hahn-echo sequence with $3.0 / 6.0 \mu \mathrm{s} 90^{\circ} / 180^{\circ} \mathrm{rf}$ pulses and 131,072 scans collected per sample using a $1 \mathrm{~s}$ relaxation delay. ${ }^{1} \mathrm{H}$ shifts were referenced with respect to tetramethylsilane (TMS) at $0 \mathrm{ppm}$, whereas ${ }^{14} \mathrm{~N}$ shifts to solid $\mathrm{NH}_{4} \mathrm{Cl}$ at $0 \mathrm{ppm}$ (-342.4 ppm with respect to nitromethane).
\end{abstract}

\title{
3.9. Mott-Schottky Measurements
}

Powder samples were assembled into particle-base thin film electrodes on fluorinedoped tin oxide (FTO) glass substrate via electrophoretic deposition. The homogeneous suspension was prepared by mixing $30 \mathrm{mg}$ powder samples and $10 \mathrm{mg}$ iodine in $30 \mathrm{~mL}$ of acetone via sonication. Two pre-cleaned FTO slides were immersed in the above suspension with $1 \mathrm{~cm}$ distance, and a DC potential of $30 \mathrm{~V}$ was applied between them for $3 \mathrm{~min}$. After Electrophoretic Deposition (EPD) process, the FTO slides with thin film were washed with water and dried naturally. $0.1 \mathrm{M} \mathrm{NaOH}(\mathrm{pH} 13)$, in which oxyhydrides are stable, was used as electrolyte to perform Mott-Schottky measurements. The measurements were conducted in the conventional three-electrode system where a platinum wire, a $1 \mathrm{M} \mathrm{Ag} / \mathrm{AgCl}$ electrode and the thin film on FTO were used as counter electrode, reference electrode and working electrode, respectively. The potentials were recorded versus $1 \mathrm{M} \mathrm{Ag} / \mathrm{AgCl}$ and converted versus reversible hydrogen electrode (RHE) according to $E_{\mathrm{RHE}}(\mathrm{V})=E_{\mathrm{Ag} / \mathrm{AgCl}}+(0.059 \times$ $\mathrm{pH})+E^{\theta} \mathrm{Ag} / \mathrm{AgCl}$. The measurements were carried out by using the Gamry INTERFACE 1010T Potentiostat/Galvanostat/ZRA workstation (Gamry Instruments, Warminster, PA, USA) in darkness at ac amplitude of $5 \mathrm{mV}$ and a frequency of $10 \mathrm{~Hz}$.

\section{Conclusions}

It was shown that reduced $\mathrm{BaTiO}_{3}$ containing simultaneously hydride and defects in the anion substructure, $\mathrm{BaTiO}_{3-x} \mathrm{H}_{y} \square_{(x-y)}$, can be readily nitrided with elemental $\mathrm{N}_{2}$ at temperatures around $450{ }^{\circ} \mathrm{C}$ to yield tetragonal phases $\mathrm{BaTiO}_{3-x} \mathrm{~N}_{(2 x / 3)-y} \square_{(x / 3)+y}$ with $\mathrm{c} / \mathrm{a} \approx 1.002$. In contrast with the nitridation of vacancy free oxyhydride $\mathrm{BaTiO}_{3-x} \mathrm{H}_{x}$, oxynitrides from $\mathrm{BaTiO}_{3-x} \mathrm{H}_{y} \square_{(x-y)}$ appear not fully nitrided and titanium remains partially as $\mathrm{Ti}^{3+}$, i.e., $y \neq 0$. Electrons are localized in traps below the conduction band. The band gap energy of $\mathrm{BaTiO}_{3-x} \mathrm{~N}_{(2 x / 3)-y} \square_{(x / 3)+y}$ materials is in a range 2.4-2.5 eV. Since the conduction band edge lies above the reduction potential for water and optical absorption is in the visible light region, it will be interesting to investigate photocatalytic properties.

Supplementary Materials: The following are available online at https:/ /www.mdpi.com/article/ 10.3390/inorganics9080062/s1, Figure S1: Rietveld fit to the PXRD data of the oxyhydride starting material $\mathrm{BaTiO}_{2.60} \mathrm{H}_{0.08} \square_{0.32}$ (BTOH), Figure S2: ${ }^{1} \mathrm{H}$ MAS NMR spectrum of BTOH showing the division into protic and hydridic signal intensity and explaining the quantification of hydridic $\mathrm{H}$ content, Figure S3: Simultaneously measured TG and DSC traces for BTOH upon heating under a dry $\mathrm{N}_{2}$ stream up to $700^{\circ} \mathrm{C}$ with a heating rate $10^{\circ} \mathrm{C} / \mathrm{min}$ and to $600^{\circ} \mathrm{C}$ with a heating rate $5^{\circ} \mathrm{C} / \mathrm{min}$, Figure S4-S13: Rietveld fits to PXRD data of BTON samples, Figure S14: Tauc plots for band gap evaluation, Table S1: Refinement result summary for BTON samples using the tetragonal structure model, Table S2: Refinement result summary for BTON samples using the cubic structure model.

Author Contributions: H.G. and U.H. conceived and designed the experiments; H.G., A.J., Z.C., C.L., performed the experiments; H.G., A.J., A.S., U.H. contributed to analyzing the data and writing the paper. All authors have read and agreed to the published version of the manuscript.

Funding: This work was supported by the Swedish Research Council (VR) through grant \#2016-03441.

Data Availability Statement: All data presented is available in this manuscript.

Acknowledgments: The authors acknowledge the financial support of the Swedish Research Council.

Conflicts of Interest: The authors declare no conflict of interest. 


\section{References}

1. Kobayashi, Y.; Hernandez, O.J.; Sakaguchi, T.; Yajima, T.; Roisnel, T.; Tsujimoto, Y.; Morita, M.; Noda, Y.; Mogami, Y.; Kitada, A.; et al. An Oxyhydride of $\mathrm{BaTiO}_{3}$ Exhibiting Hydride Exchange and Electronic Conductivity. Nat. Mater. 2012, 11, 507-511. [CrossRef]

2. Masuda, N.; Kobayashi, Y.; Hernandez, O.; Bataille, T.; Paofai, S.; Suzuki, H.; Ritter, C.; Ichijo, N.; Noda, Y.; Takegoshi, K.; et al. Hydride in $\mathrm{BaTiO}_{2} .5 \mathrm{H} 0.5$ : A Labile Ligand in Solid State Chemistry. J. Am. Chem. Soc. 2015, 137, 15315-15321. [CrossRef] [PubMed]

3. Yajima, T.; Takeiri, F.; Aidzu, K.; Akamatsu, H.; Fujita, K.; Yoshimune, W.; Ohkura, M.; Lei, S.; Gopalan, V.; Tanaka, K.; et al. A Labile Hydride Strategy for the Synthesis of Heavily Nitridized $\mathrm{BaTiO}_{3}$. Nat. Chem. 2015, 7, 1017-1023. [CrossRef]

4. Kobayashi, Y.; Tang, Y.; Kageyama, T.; Yamashita, H.; Masuda, N.; Hosokawa, S.; Kageyama, H. Titanium-Based Hydrides as Heterogeneous Catalysts for Ammonia Synthesis. J. Am. Chem. Soc. 2017, 139, 18240-18246. [CrossRef]

5. Bräuniger, T.; Müller, T.; Pampel, A.; Abicht, H.-P. Study of Oxygen-Nitrogen Replacement in BaTiO 3 by $14 \mathrm{~N}$ Solid-State Nuclear Magnetic Resonance. Chem. Mater. 2005, 17, 4114-4117. [CrossRef]

6. Müller, T.; Großmann, T.; Abicht, H.-P. Nitrogen Containing Barium Titanate: Preparation and Characterisation. J. Phys. Chem. Solids 2009, 70, 1093-1097. [CrossRef]

7. Yamamoto, T.; Kageyama, H. Hydride Reductions of Transition Metal Oxides. Chem. Lett. 2013, 42, 946-953. [CrossRef]

8. Hayward, M.A. Topochemical Reactions of Layered Transition-Metal Oxides. Semicond. Sci. Technol. 2014, 29, 29. [CrossRef]

9. Kobayashi, Y.; Li, Z.; Hirai, K.; Tassel, C.; Loyer, F.; Ichikawa, N.; Abe, N.; Yamamoto, T.; Shimakawa, Y.; Yoshimura, K.; et al. Gas Phase Contributions to Topochemical Hydride Reduction Reactions. J. Solid State Chem. 2013, 207, 190-193. [CrossRef]

10. Hernden, B.C.; Lussier, J.A.; Bieringer, M. Topotactic Solid-State Metal Hydride Reductions of $\mathrm{Sr}_{2} \mathrm{MnO}_{4}$. Inorg. Chem. 2015, 54, 4249-4256. [CrossRef] [PubMed]

11. Nedumkandathil, R.; Jaworski, A.; Grins, J.; Bernin, D.; Karlsson, M.; Eklof-Osterberg, C.; Neagu, A.; Tai, C.-W.; Pell, A.J.; Haussermann, U. Hydride Reduction of $\mathrm{BaTiO}_{3}-\mathrm{Oxyhydride} \mathrm{Versus} \mathrm{O} \mathrm{Vacancy} \mathrm{Formation.} \mathrm{ACS} \mathrm{Omega} \mathrm{2018,} \mathrm{3,} \mathrm{11426-11438.}$ [CrossRef]

12. Guo, H.; Jaworski, A.; Ma, Z.; Slabon, A.; Bacsik, Z.; Nedumkandathil, R.; Häussermann, U. Trapping of Different Stages of $\mathrm{BaTiO}_{3}$ Reduction with LiH. RSC Adv. 2020, 10, 35356-35365. [CrossRef]

13. Adam, J.; Klein, G.; Lehnert, T. Hydroxyl Content of $\mathrm{BaTiO}_{3}$ Nanoparticles with Varied Size. J. Am. Ceram. Soc. 2013, 96, 2987-2993. [CrossRef]

14. Atakan, V.; Chen, C.-W.; Paul, R.; Riman, R.E. Quantification of Hydroxyl Content in Ceramic Oxides: A Prompt Gamma Activation Analysis Study of $\mathrm{BaTiO}_{3}$. Anal. Chem. 2008, 80, 6626-6632. [CrossRef] [PubMed]

15. DiDomenico, M.; Wemple, S.H.; Porto, S.P.S.; Bauman, R.P. Raman Spectrum of Single-Domain BaTiO3. Phys. Rev. 1968, 174, 522-530. [CrossRef]

16. Venkateswaran, U.D.; Naik, V.M.; Naik, R. High-Pressure Raman Studies of Polycrystalline BaTiO 3 . Phys. Rev. B 1998, 58, 14256-14260. [CrossRef]

17. Jiang, Y.-J.; Zeng, L.-Z.; Wang, R.-P.; Zhu, Y.; Liu, Y.-L. Fundamental and Second-Order Raman Spectra of BaTiO 3 . J. Raman Spectrosc. 1996, 27, 31-34. [CrossRef]

18. An, W.; Liu, T.H.; Wang, C.H.; Diao, C.L.; Luo, N.N.; Liu, Y.; Qi, Z.-M.; Shao, T.; Wang, Y.-Y.; Jiao, H. Assignment for Vibrational Spectra of $\mathrm{BaTiO}_{3}$ Ferroelectric Ceramic Based on the First-Principles Calculation. Acta Phys. Chim. Sin. 2015, 31, 1059-1068.

19. Pokorný, J.; Pasha, U.M.; Ben, L.; Thakur, O.P.; Sinclair, D.C.; Reaney, I.M. Use of Raman Spectroscopy to Determine the Site Occupancy of Dopants in $\mathrm{BaTiO}_{3}$. J. Appl. Phys. 2011, 109, 114110. [CrossRef]

20. Hayashi, H.; Nakamura, T.; Ebina, T. In-Situ Raman Spectroscopy of $\mathrm{BaTiO}_{3}$ Particles for Tetragonal-Cubic Transformation. J. Phys. Chem. Solids 2013, 74, 957-962. [CrossRef]

21. Chávez, E.; Fuentes, S.; Zarate, R.A.; Padilla-Campos, L. Structural Analysis of Nanocrystalline BaTiO 3 . J. Mol. Struct. 2010, 984, 131-136. [CrossRef]

22. Cordes, N.; Bräuniger, T.; Schnick, W. Ammonothermal Synthesis of EAMO ${ }_{2} \mathrm{~N}(\mathrm{EA}=\mathrm{Sr}, \mathrm{Ba} ; \mathrm{M}=\mathrm{Nb}$, Ta) Perovskites and $14 \mathrm{~N}$ Solid-State $\mathrm{NMR}$ Spectroscopic Investigations of $\mathrm{AM}(\mathrm{O}, \mathrm{N})_{3}(\mathrm{~A}=\mathrm{Ca}, \mathrm{Sr}, \mathrm{Ba}, \mathrm{La})$. Eur. J. Inorg. Chem. 2018, 2018, 5019-5026. [CrossRef]

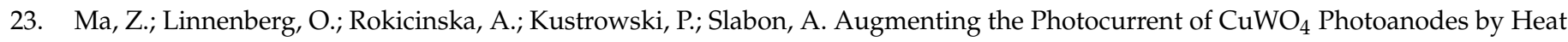
Treatment in the Nitrogen Atmosphere. J. Phys. Chem. C 2018, 122, 19281-19288. [CrossRef]

24. Ma, Z.; Lu, C.; Chen, J.; Rokicińska, A.; Kuśtrowski, P.; Coridan, R.; Dronskowski, R.; Slabon, A.; Jaworski, A. CeTiO 2 N Oxynitride Perovskite: Paramagnetic 14N MAS NMR without Paramagnetic Shifts. Z. Für Naturforschung B 2021, 76, 275-280. [CrossRef]

25. Kim, Y.-I.; Paik, Y. Bond Covalency in Perovskite Oxynitrides $\mathrm{ATaO}_{2} \mathrm{~N}$ (A = Ca, Sr, Ba) Studied by ${ }^{14} \mathrm{~N}$ NMR Spectroscopy. Solid State Sci. 2012, 14, 580-582. [CrossRef]

26. Wemple, S. Polarization fluctuations and optical-absorption edge in $\mathrm{BaTiO}_{3}$. Phys. Rev. B 1970, 2, 2679. [CrossRef]

27. Suzuki, K.; Kijima, K. Optical Band Gap of Barium Titanate Nanoparticles Prepared by RF-Plasma Chemical Vapor Deposition. Jpn. J. Appl. Phys. PART 1-Regul. Pap. BRIEF Commun. Rev. Pap. 2005, 44, 2081-2082. [CrossRef]

28. Sanna, S.; Thierfelder, C.; Wippermann, S.; Sinha, T.P.; Schmidt, W.G. Barium Titanate Ground- and Excited-State Properties from First-Principles Calculations. Phys. Rev. B 2011, 83, 054112. [CrossRef] 
29. Balaz, S.; Porter, S.H.; Woodward, P.M.; Brillson, L.J. Electronic Structure of Tantalum Oxynitride Perovskite Photocatalysts. Chem. Mater. 2013, 25, 3337-3343. [CrossRef]

30. Ebbinghaus, S.G.; Abicht, H.-P.; Dronskowski, R.; Müller, T.; Reller, A.; Weidenkaff, A. Perovskite-Related Oxynitrides-Recent Developments in Synthesis, Characterisation and Investigations of Physical Properties. Ion. Solid Solut.-Mix. Solid State 2009, 37, 173-205. [CrossRef]

31. Fuertes, A. Chemistry and Applications of Oxynitride Perovskites. J. Mater. Chem. 2012, 22, 3293-3299. [CrossRef]

32. Fuertes, A. Nitride Tuning of Transition Metal Perovskites. APL Mater. 2020, 8, 020903. [CrossRef]

33. Grundmann, M. The Physics of Semiconductors; Chapter 9; Springer: Berlin/Heidelberg, Germany, 2006.

34. Amano, F.; Nakata, M.; Yamamoto, A.; Tanaka, T. Effect of $\mathrm{Ti}^{3+}$ Ions and Conduction Band Electrons on Photocatalytic and Photoelectrochemical Activity of Rutile Titania for Water Oxidation. J. Phys. Chem. C 2016, 120, 6467-6474. [CrossRef]

35. Granhed, E.J.; Lindman, A.; Eklof-Osterberg, C.; Karlsson, M.; Parker, S.F.; Wahnstrom, G. Band vs. Polaron: Vibrational Motion and Chemical Expansion of Hydride Ions as Signatures for the Electronic Character in Oxyhydride Barium Titanate. J. Mater. Chem. A 2019, 7, 16211-16221. [CrossRef]

36. Schnabel, C.; Worner, M.; Gonzalez, B.; del Olmo, I.; Braun, A. Photoelectrochemical Characterization of p- and n-Doped Single Crystalline Silicon Carbide and Photoinduced Reductive Dehalogenation of Organic Pollutants at p-Doped Silicon Carbide. Electrochim. Acta 2001, 47, 719-727. [CrossRef]

37. Rodriguez-Carvajal, J. FULLPROF: A Program for Rietveld Refinement and Pattern Matching Analysis. In Proceedings of the Satellite Meeting on Powder Diffraction of the XV Congress of the IUCr, Toulouse, France, 19-28 July 1990; Volume 127.

38. Hwang, T.; van Zijl, P.; Garwood, M. Fast Broadband Inversion by Adiabatic Pulses. J. Magn. Reson. 1998, 133, 200-203. [CrossRef] [PubMed]

39. Kervern, G.; Pintacuda, G.; Emsley, L. Fast Adiabatic Pulses for Solid-State NMR of Paramagnetic Systems. Chem. Phys. Lett. 2007, 435, 157-162. [CrossRef] 